Rev. ANPOLL, n. 8, p. 87-102, jan./jun. 2000

\title{
HERANÇAS - A EDUCAÇÃO NO BRASII COLÔNIA
}

\author{
Leonor Lopes Fávero
}

RESUMO: O trabalho examina a educaçāo no Brasil colônia, destacando dois periodos:

- jesuítico: a identidade entre a obra dos jesuitas e a politica da coroa influi na administraçāo e no aproveitamento dos bens.

- pombalino: os jesuitas começam a agir de forma independente, intensificando-se os conflitos e provocando o rompimento pelo Marquês de Pombal, que os expulsa de Portugal e de suas colonias.

Como conseqüència dessa expulsāo, torna-se inevitável a reforma dos estudos menores em 1759. substituindo-se uma escola que serve à fé por uma que serve ao Estado; é o inicio do ensino público no sentido restrito.

PALAVRAS-CHAVE: educação; conflito entre jesuitas e coroa; reforma do ensino; escola pública x escola religiosa.

\section{O período jesuítico}

om o objetivo de tornar possivel o povoamento, a defesa e a propagação da fé e diante das dificuldades de arcar com as despesas da colonização, D. João III criou, em 1532, o regime de capitanias hereditárias e, em 1548, o Governo Geral, para apoiá-las. Dentre as diretrizes da nova politica, encontrava-se uma referente à conversāo dos indigenas, pela catequese e instrução:

\footnotetext{
- Universidade de São Paulo/CNPq.
} 
FÁVERO, Leonor Lopes. Heranças - a educaçāo no Brasil colônia.

“...a principal coisa que me moveu a mandar povoar as ditas terras do Brasil foi para que a gente dela se convertesse à nossa santa fé catölica".

Mattos (1958: 31) ressalta a importância dessa diretriz, afirmando que dela dependeria.

“...o êxito da arrojada empresa colonizadora; pois que, somente pela aculturaçāo sistemática e intensiva do elemento indigena aos valores espirituais e morais da civilizaçāo ocidental e cristã è que a colonização portuguesa poderia lançar raizes definitivas..."

Assim, com Tomé de Souza, em 1549, chegaram seis religiosos chefiados por Nóbrega.

A educaçāo na colônia estava vinculada à politica colonizadora de Portugal cujo objetivo era a obtençāo do lucro e, se nas diretrizes básicas estava citada expressamente a população indigena (para catequese e instrução), a vinda de pessoas da pequena nobreza para organizar a "empresa" exigia que se incluissem, na empreitada a que se propuseram os jesuitas, os filhos dos colonos, já que recebiam subsidios para fundar colégios.

E no dizer do mesmo Mattos (id: 84-5), Nóbrega planejava

"Recolhimentos nos quais se educassem os mamelucos, os órfãos e os filhos dos principais da terra (...) além dos filhos dos colonos brancos dos povoados".

e

“...dentre os de maiores habilidades contava também Nóbrega recrutar as vocaçōes sacerdotais indigenas" (p. 86).

Porém, como afirma Ribeiro (1988: 22):

"Como cedo perceberam a nāo-adequaçāo do indio para a formaçāo sacerdotal católica, esta percepção não deve ter deixado 
de exercer influência na proposição de um ensino profissional e agricola, ensino este que parecia a Nóbrega imprescindivel para formar pessoal capacitado em outras funçōes essenciais à vida da colônia".

O gráfico apresentado por essa autora (id: 23) ilustra bem o plano de Nóbrega cuja execuçāo exigiu muito empenho de seu autor desde 1536, ano das Constituiçōes da Companhia de Jesus, até sua morte em 1570, revelando que ele se chocava com as orientaçōes dos jesuitas, fato comprovado a partir de sua morte, quando foram excluidas as partes iniciais e o aprendizado profissional, agricola e musical (canto orfeônico e instrumental):

\section{Plano de Estudo}

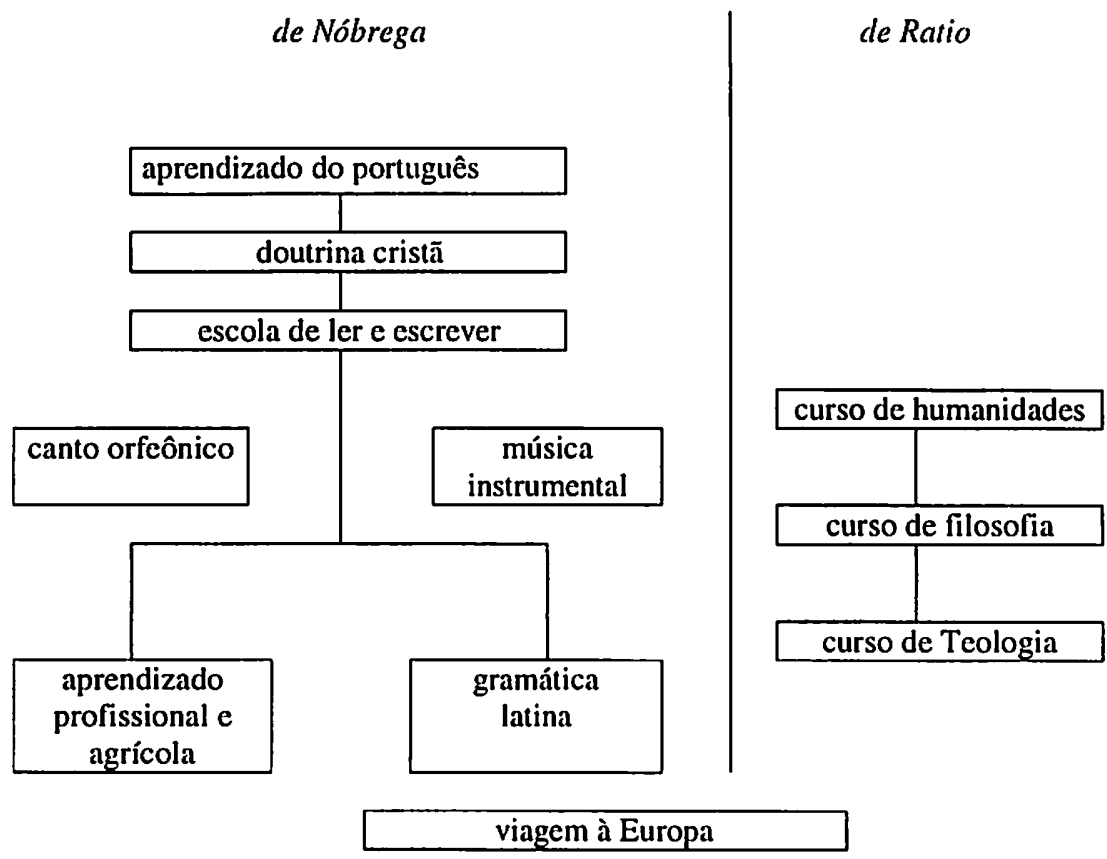

Os jesuitas mostraram, desde logo, muito empenho no ensino das primeiras letras, talvez por perceberem que o trabalho de catequese 
FÁVERO, Leonor Lopes. Heranças - a educação no Brasil colônia.

não podia prescindir do ensino da leitura e da escrita. Responsabilizaram-se pela educação dos filhos dos senhores de engenho, dos colonos, dos indios e dos escravos, procurando transformá-los em cristãos, acenando-lhes com o céu por prêmio, ou, com o inferno, aos que se recusassem. Procuravam atrair primeiro as crianças, pondoas em contato com crianças órfãs vindas de Portugal, aprendiam sua lingua e a ensinavam nos colégios.

O conhecimento do tupi era exigido dos aspirantes à Companhia de Jesus e o desconhecimento do latim passou a ser considerado de menor importância se o candidato fosse versado na "lingua brasílica", que no Brasil substitui o grego, estudado nos cursos de humanidades nos colégios jesuiticos da Europa.

A Congregação Provincial de 1568 assim se expressava:

"Scire namquam linguam brasilicam videtur esse pars ut cum illis facilius possent dispersari; dummodo virtute et aliis bonis partibus sint ornati" (Congregação, 41: 299, apud Leite 1940: 563).

Nesse periodo foram escritas duas gramáticas do tupi:

- Arte da Gramática da lingua mais usada na costa do Brasil, do Padre José de Anchieta, escrita em São Paulo de Piratininga entre 1553 e 1555, provavelmente em latim, utilizada nos colégios da Companhia, por determinaçāo do visitador, pois, como já disse, o estudo do tupi era obrigatório para os aspirantes ao sacerdócio; os que soubessem latim deveriam exercitar-se na obra, o que mostra ter sido ela escrita em latim e posteriormente traduzida para o português, por seu autor.

- Arte da lingua brasílica, do Padre Luis Figueira, publicada provavelmente em 1621 (a ediçāo não traz o ano da impressāo, mas a aprovação para ser publicada é de 1620), escrita em português e de largo uso entre os jesuitas e os literatos 
da fase indigenista do século XIX, já que a de Anchieta era rarissima e sua segunda edição só saiu em 1874 .

Após as aulas de primeiras letras, os colégios ofereciam três cursos, seguindo as determinaçōes da Ratio Studiorum, documento publicado em 1599 e que fixava as diretrizes da educaçāo jesuítica, distribuindo o curriculo escolar em dois ciclos. O primeiro, correspondente ao secundário, dividia-se em cinco classes: três de gramática (garantir a expressão exata), uma de humanidades (garantir a expressão elegante), uma de retórica (assegurar a expressão persuasiva) e se estendia por cinco ou seis anos. O segundo, correspondendo ao superior, compreendia três anos de filosofia e quatro de teologia. A formação humanistica precedia aos estudos de ciências (matemática, astronomia e física), permitindo-nos compreender a importância da formação do letrado em Portugal e no Brasil colonial.

A gramática, sinônimo de gramática latina, e segundo propunha a obra de Manuel Álvares

"era ensinada, normalmente em três classes: infima, média e suprema. $\mathrm{Na}$ infima, aprendiam-se os elementos e as regras gerais da sintaxe; na média, estudavam-se, de um modo geral, todas as partes da gramática e, na superior, este estudo aprofundava-se com a análise dos problemas da prosódia latina e de todos os demais aspectos da gramática, com o auxilio dos inúmeros trabalhos que serviam de glosas e comentários à Arte alvarista. Terminado o curso de gramática, em três ou quatro anos, passavam os alunos para a classe de humanidades, na qual se estudavam a histöria, a poesia e a retörica".

O vernáculo limitava-se às escolas de ler e escrever, mantidas pelos jesuítas às portas da universidade, ou era ensinado nas casas de familia abastadas por mestres particulares. No Brasil, o comum era que as primeiras letras fossem adquiridas também nas casas de familia dos senhores de engenhos e só, excepcionalmente, havia es- 
FÁVERO, Leonor Lopes. Heranças - a educação no Brasil colônia.

colas de ler e escrever nos colégios, para alunos que delas necessitassem, já que seu dominio era condição indispensável para o curso de humanidades. (Fávero, 1993)

A orientação da Ratio Studiorum deveria ser seguida onde quer que os jesuitas estivessem. Como se lê em Franca (1960: 132), a regra 34 do Provincial rezava que dada a variedades de lugares e pessoas

"pode ser necessária alguma diversidade na ordem e no tempo consagrado aos estudos, nas repetições, disputas e outro exercicio e ainda nas fërias, se julgar conveniente, na sua Pronúncia, alguma modificaçāo para maior progresso nas letras, informe o Geral para que se tomem as determinações acomodadas a todas as necessidades, de modo, porem, que se aproximem o mais possivel da organização geral dos nossos estu$\operatorname{dos}^{n}$.

Observa-se que educaçāo era uma educação à européia que excluia a instrução do índio (talvez por terem constatado sua impossibilidade) e, considerando os poucos recursos humanos, era necessário concentrá-los em "pontos estratégicos": os filhos dos colonos em detrimento do índio, os futuros sacerdotes em detrimento do leigo.

Assim, os colégios jesuiticos foram os formadores da elite colonial, proporcionando instrução aos descendentes dos colonizadores. Aos indios restava a catequese.

"O privilegiamento do trabalho intelectual em detrimento do manual afastava os alunos dos assuntos e problemas relativos à realidade imediata, distinguia-os da maioria da população que era escrava e iletrada e alimentava a idéia de que o mundo civilizado estava "lá fora" e servia de modelo. Os "letrados" acabavam por rejeitar não apenas esta maioria, a exercer sobre ela uma eficiente dominação, como também a própria realidade colonial, contribuindo para a manutençāo deste traço de dominação externa e nāo para sua superação". (Ribeiro, id: 27). 
Embora a formaçāo da elite colonial estivesse de acordo com a politica de Portugal, foi a Companhia de Jesus a maior beneficiária, pois, por suas Constituições, somente os Colégios e as Casa de Formação podiam possuir bens que garantissem o sustento, bens esses advindos quase exclusivamente do "Padrāo de Redizima", estipulado em 1564 (10\% de toda a arrecadação dos dizimos reais ficavam destinados, de forma inalienável a esses colégios e casas de formação, garantindo assim o sustento dos religiosos.

"Não resta dúvida que a expansão do ensino jesuitico, no reino como nos dominios portugueses, foi condicionada por este relevante fator. A penetração e o alargamento da obra missionária dependiam, fundamentalmente, da criação de escolas, únicos empreendimentos que poderiam justificar, do ponto de vista canônico, a posse dos bens indispensáveis à concretização dos demais fins da Companhia de Jesus". (Carvalho, id: 110).

Quando de sua expulsão, os inacianos possuiam, no Brasil, segundo Azevedo (1944: 312) trinta e seis residências, trinta e seis missōes, dezessete colégios além de seminários e escolas de ler e escrever e, no dizer de J. Lúcio de Azevedo (1922),

"a obra que haviam empreendido tinha caráter temporal e, nessa
qualidade somente com meios materiais se poderia realizar. A
sociedade religiosa era, pois, tambèm mercantil"

Nāo foram os jesuitas únicos religiosos que aqui mantiveram casas de ensino. Holanda (1960: 76) informa que "outras ordens religiosas alcançaram também regalias que lhes permitiram realizar, como complemento de seus objetivos confessionais, um trabalho de educaçāo secular".

Fica claro, porém, que, até as reformas introduzidas por Pombal, o ensino se caracterizava pelos interesses religiosos e nāo pelos da sociedade civil. 
FÁVERO, Leonor Lopes. Heranças - a educação no Brasil colônia.

O mesmo autor nos dá conta de que, provavelmente já antes de 1730, os franciscanos mantinham escolas de primeiras letras e gramática em Cabo Frio, Macacu e Taubaté. Havia também conventos em Vitória, Rio de Janeiro (um curso de Artes e Teologia), Sāo Paulo e em Itu, ao Sul e, no Norte e Nordeste, em Igaraçu, Alagoas, Penedo, Sāo Cristóvāo, Cairu e Serinhaém. O que não se sabe com certeza é se os estudos mantidos nesses conventos eram destinados apenas à formação sacerdotal.

Beneditinos e carmelitas também mantiveram casas de ensino. Segundo D. Joaquim G. de Luna (apud Holanda, id: 77), "os estudos clássicos dos monges (beneditinos), isto é, os cursos de filosofia e teologia, eram feitos nos mosteiros da Bahia, Rio de Janeiro e Olinda, mas, parece, nāo simultaneamente nas três abadias, porém quase sempre em duas ao mesmo tempo". Poucas são as noticias sobre os cursos de gramática e humanidades que, certamente, deveria haver, pois eram condiçāo para ingresso nos estudos maiores. Quanto aos carmelitas, mantiveram colégios em Olinda e no Maranhão, transferido este último posteriormente para Belém. Além dos cursos regulares, havia cursos de lingua indigena nos colégios carmelitas.

Nenhuma congregação religiosa, porém, realizou, no campo do ensino, trabalho tão eficiente quanto o dos jesuitas que se integraram desde os primeiros tempos à politica colonizadora da metrópole e foram, por mais de dois séculos, praticamente os únicos responsáveis pela educação no Brasil. Sua expulsão de Portugal e colônias vai provocar, necessariamente, a reforma dos estudos menores.

\section{O período pombalino}

No século XVIII, pretendeu-se em Portugal, a restauração do poder (interna e externamente) e a melhoria das condições de vida da populaçāo prejudicada por muitos anos de dominio espanhol. 
Rev. ANPOLL, n. 8, p. 87-102, jan./jun. 2000

"A Península Ibérica oferece-nos uma situaçāo paradoxal. De certo modo verificou-se ali, já no final da Idade Média, uma 'modernização' precoce, apoiada que foi na centralização monárquica e no desenvolvimento do absolutismo, paralelamente à gigantesca empresa maritima, mercantil e colonial, na qual coube ao Estado uma participaçāo efetiva e nāo raro decisiva". (Falcon, 1989: 149).

Porém, se as conquistas ultramarinas permitiram um enriquecimento em relação a outras naçōes européias, a má administração do ouro e dos diamantes do Brasil e das riquezas do comércio com o Oriente provocou a decadência, decadência essa que já se prenunciava no governo de $\mathrm{D}$. Manuel e que se evidenciou com a dominação espanhola.

Sobre ela, assim se expressou Prado Jr. (1969: 49):

"Portugal sairia arruinado da dominação espanhola, a sua marinha destruida o seu império colonial esfacelado (..) Efetivamente, só lhe sobraria o antigo império ultramarino, o Brasil e algumas posses na África. Estas aliás só valerão como fornecedores de escravos para o Brasil".

$\mathrm{E}$

"Quando os diamantes e o ouro do Brasil vinham inundar Portugal de riquezas [...] entāo era preciso entulhar de frades, de capelāes, de cônegos, de monsenhores, de principes, de escribas, de desembargadores, de caturras, de rimadores de epitalâmios e de elegias, o insondável sorvedouro das inutilidades públicas. Como de outro modo devorar as entranhas da América? Esta era a grande indústria portuguesa de então; para ela se deviam organizar os estudos. O Tesoiro do Estado substituia a açāo dos homens. Com agentes espertos para vender diamantes na Holanda e obreiros hábeis para cunhar oiro nos paços da moeda, estavam supridos trabalhos, educação do povo, actividade, tudo". (Herculano, apud A. Sérgio, 1972: 122).

O reinado de D. João V (1707-1750) caracterizou-se pelo crescimento do absolutismo monárquico e pela hegemonia eclesiática 
FÁVERO, Leonor Lopes. Heranças - a educação no Brasil colônia.

sobre a sociedade civil, o que vai acarretar, no final do milênio, um enfraquecimento do poder real em termos de autoridade, o que permitia o aparecimento de atitudes de autonomia como reduçāo dos quintos e a intensificação do contrabando, acarretando diminuiçāo dos lucros da metrópole. Nos discursos de D. Luis da Cunha e de Alexandre de Gusmão, aparece claramente a preocupação com a questão (Fâvero, 1996).

Por esta razāo, com a ascensão ao trono de D. José I, em 1750, seu primeiro ministro Sebastião José de Carvalho e Melo (futuro Marquês de Pombal) tomou sérias decisões no sentido de reafirmarse o poder do Estado absolutista: fortalecimento do poder real e estimulo à indústria, permitindo a recuperaçāo dos lucros e a reorganização do comércio.

No inicio de seu governo, Pombal não tinha nenhum plano contra os jesuitas. Segundo Carvalho (id: 41)

“[...] o anti-jesuitismo fol muito mais a conseqüência das lutas politicas do gabinete com a Cúria Romana do que a verdadeira causa do programa pedagógico formulado pela Junta de Providência Literária. Tamanha foi a força das vicissitudes politicas, e tão acirrados andavam os ânimos, que um programa, para cuja justificação bastava apenas a incontestável grandeza de seus fins, se transformou, impelido pelas circunstancias históricas, num documento com deliberados propósitos de fazer dos jesuitas a universal causa de todos os males portugueses".

Assim, a luta de Pombal contra os jesuitas foi causada inicialmente pelos conflitos de interesses entre o Estado e a Companhia de Jesus.

No Brasil, segundo Holanda (op. cit.: 78),

"duas foram principalmente as questōes que acirraram a disputa entre Pombal e os jesuitas: a primeira nasceu da resistência ao plano de libertação dos indios e secularização das missōes eclesiásticas; a Segunda, dos sucessos relacionados com 
o cumprimento do tratado de limites entre Portugal e Espanha no reinado de $\mathrm{D}$. João $\mathrm{V}^{\prime \prime}$.

A resistência dos jesuitas aos propósitos de Pombal fizeram com que os atritos ocorressem com freqüência cada vez maior já que o ministro se mostrava firmemente disposto a defender os interesses da coroa e os jesuitas, como reconhece S. da Silva Leite (1938), "pelas condiçōes particulares da América não puderam ser o que foram na Ảsia, apenas missionários: foram também colonizadores".

"A expulsão dos jesuitas do Grão-Pará foi apenas o prenúncio
da expulsão geral de 1759 . Desfazia-se assim a tradicional po-
litica missionária e colonizadora que desde o reinado de D. João
III assegurara à Companhia de Jesus os meios de sua extraor-
dinária expansão em terras brasileiras". (Holanda, op. cit.: 80 ).

Ao suprimir o ensino dos jesuitas, Pombal, não subestimando a luta em que se empenhara, sabia que precisava supri-los imediatamente; dai, como já disse, e reforma dos estudos menores, corporificada no Alvará Régio de 28 de junho de 1759.

A reforma, ao mesmo tempo em que extinguia todas as escolas dirigidas pelos jesuitas, criava o cargo de diretor geral dos estudos e estabelecia aulas régias de latim, grego e retórica pelo novo método. que era o dos oratorianos (em 1752, é publicado o Novo método de gramática latina pelos padres da Congregação do Oratório), proibindo o alvarista, dada a "necessidade de se conservarem a uniāo cristã e a sociedade civil".

Não há ainda a acusação de que eram os jesuitas os causadores de todos os males; esta acusação só vai aparecer na Dedução Cronológica, em 1765.

As principais medidas eram:

- criação do cargo de Diretor Geral dos estudos, ao qual ficavam subordinados os professores; 
FÁVERO, Leonor Lopes. Heranças - a educaçāo no Brasil colônia.

- determinaçāo de que todos os professores prestassem exames para serem aceitos;

- obrigatoriedade, quer para o ensino público, quer para o particular, de licença do Diretor Geral de Estudos;

- proibição do uso do livro de Manuel Álvares ou de seus comentadores e da Prosódia de Bento Pereira "pelo perigo que se há de imprimir logo nos primeiros anos a multidão de palavras bárbaras de que está cheio" (§ XII);

- estabelecimento, para os professores, dos Privilégios de Nobres, incorporados ao Direito comum, e especialmente no Código, Título - De professoribus et medicis.

Substitui-se, assim, uma escola que servia à fé, por uma que servia ao Estado.

Segundo Valnir Chagas (1980: 9)

"Pior é que, para substituir a monolítica organizaçāo da Companhia de Jesus, algo tão fluido se concebeu que, em última análise nenhum sistema passou a existir. No reino, seria instalada uma longinqua e ausente Diretoria de Estudos que, em rigor, só começaria a operar após o afastamento de Pombal; na colônia imensa, uma congérie de aulas régias superintendidas pelo Vice-Rei. Cada aula régia constituía uma unidade de ensino, com professor único, instalada para determinada disciplina. Era autônoma e isolada, pois não se articulava com outras nem pertencia a qualquer escola. Não havia curriculo, no sentido de um conjunto de estudos ordenados e hierarquizados, nem a duraçāo prefixada se condicionava ao desenvolvimento de qualquer matéria. $O$ aluno se matriculava em tantas 'aulas' quantas fossem as disciplinas que desejasse. Para agravar esse quadro, os professores eram geralmente de baixo nivel, porque improvisados e mal pagos, em contraste com o magistério dos jesuitas, cujo preparo chegava ao requinte. Nomeados em regra por indicação ou sob concordância de bispos, tornavam-se 'proprietários' das respectivas aulas régias que lhes eram atribuidas, vitaliciamente, como sesmarias ou titulos de nobreza". 
As dificuldades para implantar as reformas foram muitas, como falta de recursos, de professores e de providências por parte do diretor geral de estudos. Em 1772, criou-se um imposto - o subsídio literário - que deveria proporcionar aos professores "decente honestidade de habitaçāo e de independência":

"O fundo monetário que há de manter este projeto pode estabelecer-se suavissimamente, e com muita satisfação dos Povos, que para ele hão de contribuir na imposiçāo de um Real em cada canada de vinho, e quartilho de aguardente, no Reino e llhas, em cada arrätel de vaca na Ásia, Amėrica e África".

Foram instituidas, em conseqüência, 17 aulas de ler e escrever: Rio de Janeiro (2), Bahia (4), Pernambuco (4), São Paulo (1), Mariana (1), Vila Rica (1), Sabará (1), São João del Rei (1), Pará (1) e Maranhāo (1); 15 aulas de gramática latina: Rio de Janeiro (2), Bahia (3), Pernambuco (4), Mariana (1), São Paulo (1), Sāo João del Rei (1), Pará (1) e Maranhão (1); 6 aulas de retórica: Rio de Janeiro, Bahia, Pernambuco, Pará, Mariana e São Paulo; 3 aulas de grego e 3 de filosofia: Rio de Janeiro, Bahia e Pernambuco (Holanda, id. )

Havia ainda, além das aulas régias, estudos regulares com disciplinas em seqüência lógica com classes organizadas, nos seminários mantidos pelas ordens religiosas, como o Seminário de Olinda, criado em 1798, com ênfase nos estudos de matemática e de ciências e que se tornou um centro de idéias liberais, tendo seus membros, alunos e professores, participado de movimentos pela independência do pais, como a revolução de 1817 .

O Alvará Régio de 1772 procurou reorganizar a universidade de Coimbra, alterando profundamente todos os seus cursos. Porém, não atingindo o Brasil, já que nāo dispúnhamos de cursos superiores, pois Portugal nunca permitiu a instalação de escolas de ensino superior na colônia.

Quando Minas Gerais pediu, em 1768, permissão para criar uma escola de medicina, o Conselho Ultramarino respondeu que a 
FÁVERO, Leonor Lopes. Heranças - a educação no Brasil colônia.

questão era politica, que uma decisão favorável poderia relaxar a dependência e que "um dos mais fortes vinculos que sustentava a dependência da colônia era a necessidade de vir estudar a Portugal". Aberto o precedente, criar-se-ia uma jurisprudência; o governo deveria dar bolsas para que os alunos pobres pudessem estudar em Portugal.

A Espanha, por sua vez, permitiu desde cedo a criação de universidades. Datam de 1551 as duas primeiras, no México e no Peru, contribuindo, assim, muito mais do que Portugal para a educação superior. Calcula-se que até o fim do periodo colonial 15.0000 pessoas tenham se diplomado pelas universidades da América espanhola, que eram 25, enquanto somente 1242 brasileiros se matricularam em Coimbra entre 1772 e 1872.

"O preço da homogeneidade da elite brasileira foi uma distribuição muito mais elitista da educação e a menor difusāo de idéias que os governos da época consideravam perigosas. Apesar do controle religioso, a maior difusão da educação superior nas colônias espanholas contribuiu também para a maior propagação das idéias do lluminismo francês, sinônimo de oposiçāo ao poder absoluto". (J. M. de Carvalho, 1996: 62).

Segundo o mesmo J. M. de Carvalho, a política educacional da Espanha permitiu a formação de uma elite intelectual em quase todas as colonias (depois paises) e possibilitou o ensino superior em grau muito maior do que o fez Portugal na sua colonia, porém

"A importância política da concentraçāo é iniludivel. Boa parte do impulso autonomista, ou mesmo separatista, de provincias e regiōes pôde ser prevenida pela formaçāo comum e pelos laços de amizade criados durante o periodo escolar. Homens como o visconde do Uruguai e o marquês do Paraná, por exemplo, dois sustentáculos da reaçāo conservadora, o primeiro nascido em Paris, o segundo em Minas Gerais, tornaram-se amigos em Coimbra, o mesmo acontecendo com vários outros. Os politicos que receberam sua formação no Brasil antes da Indepen- 
dência, sobretudo os padres, tendiam a se preocupar muito menos com a unidade do pais e com o fortalecimento do poder central".

(ibid. )

Este quadro só começa a mudar com a chegada da Corte em 1808, mas os dois cursos de Direito (São Paulo e Olinda) são criados somente em 1827.

\begin{abstract}
This work analyses the Colonial Brazil Education, sharing it in two periods:

- jesuitical period: the identity between the jesuitical work and the crown polithycs infuences in the administration and in the landed property's utilization.

- Pombal period: jesuits stated an independent process, the confits were improved and Pombal stopped the relationship with them, and ordered them to get out of Portugal and its possessions.

As a consequence, the process of a changing in secundary school methods of studying was irreversible in 1759, substituing a pray serven school for a state serven school. It's the strict prove of start of the public teaching.
\end{abstract}

KEYWORDS: education; conflict between jesuits and the crown; change of the teaching methods; public school $x$ religious school.

\title{
Bibliografia
}

AZEVEDO, F. de (1944) A cultura brasileira: introduçāo ao estudo da cultura no Brasil. 2. ed. São Paulo: Companhia Editora Nacional.

AZEVEDO, J. L. de (1922) O marquês de Pombal e a sua época. Rio de Janeiro/Lisboa: Anuário do Brasil/Seara Nova/Renascença Portuguesa.

CARVALHO, J. M. de (1996) A construçāo da ordem. 2. ed. Rio de Janeiro: Editora UFRJ, Relume-Dumará.

CARVALHO, L. R. de (1978) As reformas pombalinas da instrução pública. Sāo Paulo: EDUSP/Saraiva. 
FÁVERO, Leonor Lopes. Heranças - a educação no Brasil colônia.

CHAGAS, V. (1980) Educaçāo brasileira: o ensino de $1^{\circ} e 2^{\circ}$ graus. 2. ed. São Paulo: Saraiva.

FÁVERO, L. L. (1996) As concepções lingüisticas no século XVIII. Campinas: Editora da UNICAMP.

FALCON, F. J. C. (1982) A época pombalina. São Paulo: Ática.

FRANCA, L. (1960). O método pedagógico dos jesuítas. Rio de Janeiro: Agir.

HOLANDA, S. B. de (org.) (1960) História geral da civilização brasileira, Tomo II. São Paulo: Companhia Editora Nacional, 6 vols.

LEITE, S. da S. (1938) História da Companhia de Jesus no Brasil: século XVI. 2. ed. Lisboa: Portugalia.

MATTOS, L. de (1958) Primórdios da educaçāo no Brasil: esboço de estudo histórico. Recife: Impressāo Universitária.

PRADO Jr., C. (1970) História econômica do Brasil. São Paulo: Brasiliense.

RIBEIRO, M. L. S. (1988) História da educaçāo brasileira. 15. ed. Campinas: Editores Associados.

SÉRGIO, A. (1972) Breve interpretação da história de Portugal. Lisboa: Sã da Costa. 